\title{
THE EFFECTS OF DIFFERENT DOSES OF ORAL CREATINE SUPPLEMENTATION ON TIBIAL MUSCLE RESISTENCE AND FATIGUE IN WISTAR RATS
}

\author{
EFEITO DE DIFERENTES DOSES DE SUPLEMENTAÇÃO DE CREATINA NA \\ RESISTENNCIA MUSCULAR E FADIGA EM RATOS WISTAR
}

\author{
Maurício Ferreira COELHO ${ }^{1}$; Rodrigo Leal de Paiva CARVALHO ${ }^{2}$; \\ Joyce Camilla SALTORATO ${ }^{2}$; Ligiane Souza dos SANTOS $^{2}$; Ricardo Henrique MARQUES ${ }^{1,3}$; \\ Rodrigo Álvaro Brandão LOPES-MARTINS ${ }^{1,3}$ \\ 1. Programa de Pós-Graduação em Engenharia Biomédica, Núcleo de Pesquisas Tecnológicas, universidade de Mogi das Cruzes - UMC, \\ Mogi das Cruzes, SP, Brazil; 2. Laboratório de Pesquisa em Fisioterapia - Programa de Mestrado em Fisioterapia, Universidade do \\ Sagrado Coração - USC, Bauru, SP, Brazil; 3. Programa de Pós-Graduação em Bioengenharia - Universidade Brasil, Itaquera, São \\ Paulo, SP, Brazil. rodrigoalvaro@umc.br
}

\begin{abstract}
The aim of the present study was to investigate the effects of different doses of oral creatine supplementation on tibial muscle resistance and fatigue in Wistar rats. The treatment protocols included swimming exercises, supplementation alone (different doses), and supplementation (different doses) + swimming exercises. Analysis of the effect of creatine supplementation on skeletal muscle fatigue was performed using the intensity of muscle contraction to electrical stimulation to evaluate the intensity of muscle contraction, decay time of muscle tetanic contraction to $50 \%$ of maximum tension (fatigue), and the area under the curve for the intensity x time ratio, besides AST, $\mathrm{LDH}$, and urea plasmatic analysis. Our results suggest that creatine supplementation seems to be able to produce ergogenic effects on contractile metabolism in the group treated with the dose of $280 \mathrm{mg} / \mathrm{kg}+$ swim exercise. This creatine dose presented a statistically significant increase in decay time of muscle tetanic contraction $(\mathrm{C} 280+\mathrm{swim}(119 \pm 13.1)$,

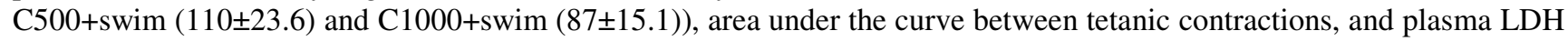
decrease, when compared to the other doses. These data clearly demonstrate that high doses do not lead to any additional ergogenic effects. We conclude that the dose of $280 \mathrm{mg} / \mathrm{kg}+\mathrm{swim}$ exercise obtained the best ergogenic effects on tibial muscle resistance and fatigue in Wistar rats.
\end{abstract}

KEYWORDS: Creatine. Exercise. Fatigue. Tetanic contraction. Dietary supplement.

\section{INTRODUCTION}

Dietary supplementation with various types of nutrients is popular and widely used, mainly by athletes. The consumption of these nutritional supplements is a phenomenon which has been growing. Supplementation aims to improve performance and recovery from training or competitions, besides improving health and aesthetic conditions (AOKI, 2004).

The use of creatine $(\mathrm{Cr})$ as a food supplement is being studied in several fields of healthcare and with different subjects such as elderly people, sick people, athletes, and people who practice exercises (ZANELLI et al., 2015). The effectiveness of $\mathrm{Cr}$ in the increase in corporal mass, performance in exercises of high intensity and exercises of short duration has been confirmed, showing it to be one of the most popular supplements in the world (BRANCH, 2003)

It is believed that $\mathrm{Cr}$ can help the maintenance of high energy phosphate during exercise, increasing performance in several activities such as high intensity exercises, repeated tasks of intensity with frequent pauses, more prolonged anaerobic tasks, and sports activities of endurance, increasing creatine phosphate $(\mathrm{PCr})$ stocks, and leading to a higher ATP resynthesis capacity (ARAÚJO et al., 2013; PERSKY; BRAZEAU, 2001; RICO-SANZ, 2000).

According to Deminice and Jordao (2012), $\mathrm{Cr}$ supplementation can decrease oxidative stress markers in plasma and muscle after a moderate aerobic exercise like swimming. Creatinesupplemented rats demonstrate antioxidant and protective effects, decreasing reactive oxygen species (ROS) when compared with rats without supplementation.

Creatine has an ergogenic effect well-known to improve exercise performance such as explosive muscle power and increased lean body mass after resistance exercise. It has been demonstrated that creatine can promote recovery by attenuating muscle damage after eccentric exercise. In addition creatine supplementation can decrease inflammatory response after muscle damage (KIM et al., 2015).

The protocols of $\mathrm{Cr}$ supplementation are varied, but studies in humans evolving $\mathrm{Cr}$ 
supplementation are usually divided into two phases: the initial phase, known as loading, with the supplementation of higher doses for 5 to 7 days, followed by, the maintenance phase, with doses reduced to $1 / 5$ of those of the initial phase, over several weeks, for which creatine monohydrate (Crm) is the most common supplement available and used in research (RICO-SANZ, 2000).

Thus, the current study aimed to evaluate the effect of supplementation with several doses of Crm, a "physiological storer" of energy, on localized muscular fatigue, and therefore demonstrate the best dose, using for this purpose the experimental model of tetanic contractions induced by indirect electrostimulation of the tibial muscle of rats.

\section{MATERIAL AND METHODS}

For this study, 48 male rats (Norvegicos Albinus) of the Wistar lineage were used, weighing around $250 \mathrm{~g}$, from the vivarium of UNIVAP. The animals were kept in standard conditions of temperature $\left(22-24^{\circ} \mathrm{C}\right)$, relative humidity $(40-60 \%)$, and 12-hour light and dark cycle, with food and water ad libitum. The rats were randomly divided into 8 groups of 7 animals. The project was approved by the Research Ethics Committee (R.E.C.) of UNIVAP, ${ }^{\circ}$ L014/2002/CEP and was carried out in accordance with the rules of the Brazilian College of Animal Experimentation COBEA and animal testing standards of the International Council for Laboratory Animal Science.

Experimental groups:

Group 01 (sedentary group): group without $\mathrm{Cr}$ supplementation, sedentary, with only application of the electrical stimulation test and collection of blood samples $(n=6)$;

Group 02 (exercise group): group without $\mathrm{Cr}$ supplementation, with exercise implementation (swimming), and subjected to application of the electrical stimulation test and collection of blood samples $(\mathrm{n}=6)$;

Group 03 (sedentary group/supplemented): this group was divided into 3 subgroups according to the drug dose. In addition to supplementation, these animals were subjected to the electrical stimulation test and collection of blood samples, without the implementation of exercises $(n=6 /$ each subgroup). The groups were:

body weight

group 3.1 (C280): dose of $280 \mathrm{mg} / \mathrm{Kg}$ of

group 3.2 (C500): dose of $500 \mathrm{mg} / \mathrm{Kg}$ of body weight group 3.3 (C1000): dose of 1000 $\mathrm{mg} / \mathrm{Kg}$ of body weight
Group 04 (exercise group/supplemented): in this group, the animals were submitted to exercise and supplementation, in addition to completion of the electrostimulation test and collection of blood samples. Like the previous group, the animals were subdivided according to the supplementation dose ( $n=6 /$ each subgroup):

group 4.1 (C280+exercise): dose of 280 $\mathrm{mg} / \mathrm{Kg}$ of body weight

group 4.2 (C500+exercise): dose of 500 $\mathrm{mg} / \mathrm{Kg}$ of body weight

group 4.3 (C1000+exercise): dose of 1000 $\mathrm{mg} / \mathrm{Kg}$ of body weight

\section{Characteristics of Supplementation}

Administered doses of $\mathrm{Cr}$, which have positive effects on high intensity exercises may vary widely, according to the literature. The doses chosen are found in the literature to be beneficial for this type of exercise (ranging from $200 \mathrm{mg} / \mathrm{kg}$ to $1000 \mathrm{mg} / \mathrm{kg}$ ). The dose of $1000 \mathrm{mg} / \mathrm{kg}$ was chosen to verify the effects of high doses of Cr (KIM et al., 2015).

The substance used was Creatine Monohydrate (Creatine Monohydrate, ProLab® Nutrition, Lot \# 161C75110800 with degree of pharmaceutical purity: 100\%). Supplementation was performed by gavage, with water as a solvent, preexercise. A high precision $(0.0001 \mathrm{mg})$ digital scale (Mettler Toledo AB-204S Digital Scale) was used for drug weighing. Immediately prior to drug weighing, weight measurement of each animal in the group to be treated was carried out, with the purpose of calculating the average weight value, to be considered in the weighing of the drug $(280,500$, or $1000 \mathrm{mg} / \mathrm{KG}$ of body weight). For the administration of supplementation, a special needle syringe with a "probe" type tip was used, which delivers the solution directly to the intragastric animal environment (gavage). All treatments took place in the morning period and lasted approximately 30 minutes per group, being performed for a period of 5 days. This period corresponds to the most commonly recommended phase of accumulation in humans (van LOON et al., 2003).

\section{Exercise Protocol}

The exercises were performed by swimming practice. As well as the supplementation, the swimming was also always held in the morning. In the groups which performed the two treatments (supplementation + swimming), a 45-minute break prior to exercise practice was respected. The swimming training was preceded by 2 weeks of 
individual adaptation to the deep water environment (keeping the animal in shallow water at $31 \pm 1 \mathrm{C}$ for $20 \mathrm{~min}, 5$ days/week for 1 week), in cylindrical tanks (80 cm diameter $\times 120 \mathrm{~cm}$ depth), subdivided into cylindrical compartments of $30 \mathrm{~cm}$ diameter $\times 120 \mathrm{~cm}$ depth for individual swimming. The adaptation to exercise consisted of $15 \mathrm{~min}$ of free swimming 3 days/week for 1 week.

\section{Training protocol}

The training protocol lasted 12 weeks with exercise sessions of $1 \mathrm{~h} /$ day, 6 days/week with 24 hours of recovery between sessions. The intensity of the training (4\% of body weight) was constant and based individually on the minimal lactate test (de Araujo et al., 2007). A load of $4 \%$ of body weight corresponds to an under-lactate threshold swimming intensity.

\section{Electrostimulation Process}

The technique used was described by Lopes-Martins et al. (2006) and Ramos et al. (2012). The procedure consists of anaesthetizing the animal with Ketamine and Xylazine (100 mg/kg and 20 $\mathrm{mg} / \mathrm{kg}$ respectively). After inducing analgesia and sedation, skin removal and dissection of the tibialis anterior muscle are performed, with the purpose of isolating the motor nerve, responsible for the stimulation of the muscle in question, which is found parallel to the tibial bone. Once the nerve is isolated, the fixation of the distal tendon to a dynamic transducer takes place that transforms the data from muscle tension into electrical signals transmitted to the physiograph. Next, following the procedure sequence, an electrode with a bipolar end is placed in contact with the motor nerve, which in turn is connected to the electrostimulator for indirect innervation of muscles. For the analysis of fatigue resistance, the electrical stimulation protocol was carried out with an initial current: 0.2 pps (pulses per second) at an intensity of 7 volts, corresponding to active muscle relaxation, interleaved every 10 minutes by tetanic stimulation: 60 pps and 7 volts. The stimulation frequency of $60 \mathrm{pps}$ was maintained until the intensity of contraction dropped to $50 \%$ of the initial maximum contraction. At this point, the stimulator was set back to a frequency of $0.2 \mathrm{pps}$, to promote active recovery of the muscle. In order to prevent the drying of the tissue, a physiological serum catheter was adapted to drip every 30 seconds or so. These tetanic contractions were performed in a total of three replicates, completing the entire protocol in 30 minutes. Transmitted data, expressed in the physiograph sheet, were measured and statistically analyzed.
In order to measure the data in the physiograph, three variables of responses obtained during the electrostimulation test were taken into account. Height of the curve (1): this variable represents the maximum force capability of muscle contraction; through it, it is possible to observe changes in voltage levels able to be generated by a particular muscle group. Length of the curve (2): this represents the length of time between the start of tetanic contraction until its amplitude reaches the value of $50 \%$ of the maximum initial contraction. Area of the curve (3): the area of the curve drawn by the resistance to fatigue represents a relationship between the degree of amplitude of the maximum contraction of the fiber and resistance to fatigue; this value tells you if the fiber has a greater ability to withstand fatigue in conditions of maximum or submaximal contraction. Besides the choice of these variables, only tetanic contractions 1,3 , and 6 were considered, that is, the initial contraction, a representation of the condition "during" the experiment, and the final tetanic contraction, which represents the moment of greatest interference of the state of fatigue in the performance of the muscles.

The stimulator used in the research was: Grass Inst. Div. Warwick, RI. Uses; the transducer of the experiment was a contraction model with dynamic character, from UGOBASILE; and the physiograph used was the GEMINI 7070 from UGOBASILE.

\section{Process of Plasmatic Biochemical Analysis}

The analysis was carried out on animal samples obtained immediately after the end of the application of electrostimulation, when approximately $3 \mathrm{ml}$ of blood were collected by cardiac puncture. Blood samples were then placed in Eppendorf tubes and immediately taken to the centrifuge (Sero-Fuge II CT1660 - ADAMS) where the serum was separated for analysis. After separation and labeling of the sample, it was sent directly to the freezer $\left(-80^{\circ}\right.$ Celsius $)$ where it remained until the analysis.

The actual analysis was performed using the test of absorbance in spectrophotometry. For this purpose, a Spectrophotometer UV / VIS Model U2001 - HITACHI was used, in addition to reaction kits for carrying out DIAGNOSTIC ANALYSIS. The kits vary according to the substance to be analyzed; for measuring urea category 227; for AST (SGPT) category 253; and for LDH category 241. Analyzes were performed in the Laboratory of Pharmacology of the Institute of Research and Development at UNIVAP. 


\section{Statistical Analysis}

Data are expressed as mean and standard deviation $( \pm)$, for normality the Shapiro-Wilk test was adopted. Data obtained were analyzed statistically by the Graphpad Prism 5 program, using the two-way ANOVA test and post-hoc TukeyKramer. The groups were all compared against each other through mean values and standard deviation with a significance level of $\mathrm{p}<0.05$.

\section{RESULTS}

In Figures 1 to 6 , the groups were divided into two graphs (Supplemented and not supplemented) for better visualization.

Figures 1 and 2 show the effects of Crm supplementation on the tibial muscle contraction intensity induced by electrical stimulation in different groups, during the three pre-determined moments.

\section{COELHO, M. F. et al.}

Initially, it is possible to observe that the sedentary/supplemented group, as well as the control group, present a reduction over the course of the first tetanic contraction (T1) to the third tetanic contraction (T3) (Figure 1). Besides this reduction, it can also be observed that there are no significant differences between the different supplemented groups, at any given time. The statistical analysis adopted considered the data comparison between the different groups at each moment. Therefore, we can affirm that the contraction intensity of the different groups (Figure 1) did not present a significant difference at any moment of the test (T1, T2, T3).

In Figure 2, all groups demonstrated improvement in the intensity of muscle contraction when compared to the sedentary group, but did not present a significant difference between them at any moment of the test.

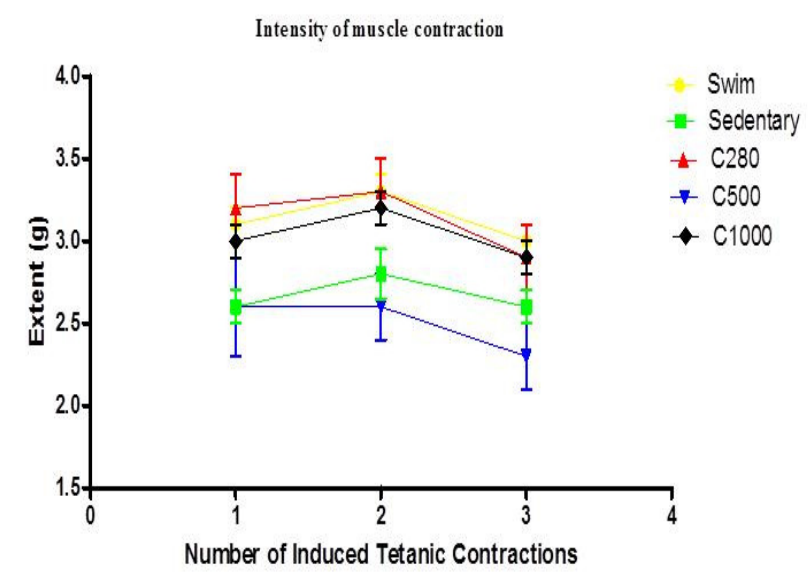

Figure 1. Intensity of muscle contraction expressed in grams of tension caused by the indirect electrical stimulation induced every 10 minutes. The graph reports the behavior of the variable in each group during the three distinct moments, contractions 1,2 , and $3(n=6)$.

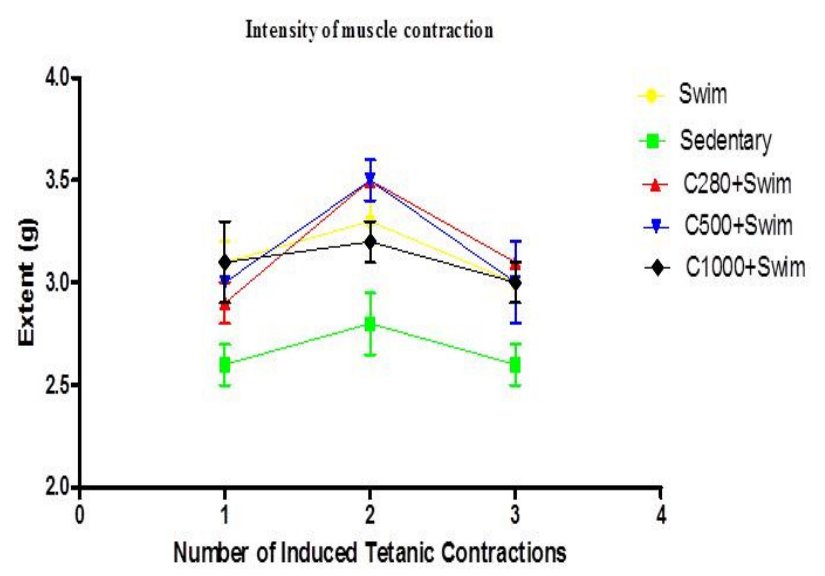

Figure 2. Intensity of muscle contraction expressed in grams of tension caused by the indirect electrical stimulation induced every 10 minutes. The graph reports the behavior of the variable in each group during the three distinct moments, contractions 1,2 , and $3(n=6)$. 
Figures 3 and 4 show the effect of $\mathrm{Crm}$ supplementation over the time (s) necessary for the contraction intensity to decline to $50 \%$ of the maximum contraction. During T1 (initial) and T3 in Figure 4, it was observed that three groups treated with creatine+swim (C280+ swim (119 \pm 13.1$), \mathrm{C} 500+$ swim (110 \pm 23.6$)$ and $\mathrm{C} 1000+$ swim $(87 \pm 15.1))$ demonstrated significant improvement when compared to all sedentary/supplemented groups (Figures 3 and 4). The C280+swim group and C500+swim group presented statistically significant differences when compared with the C1000+swim group at T1 and T2; however the C280+swim group showed significant improvement when compared to the C500+swim and C1000+swim groups at T3 (Figure 4).

Decay Time of muscle tetanic contraction

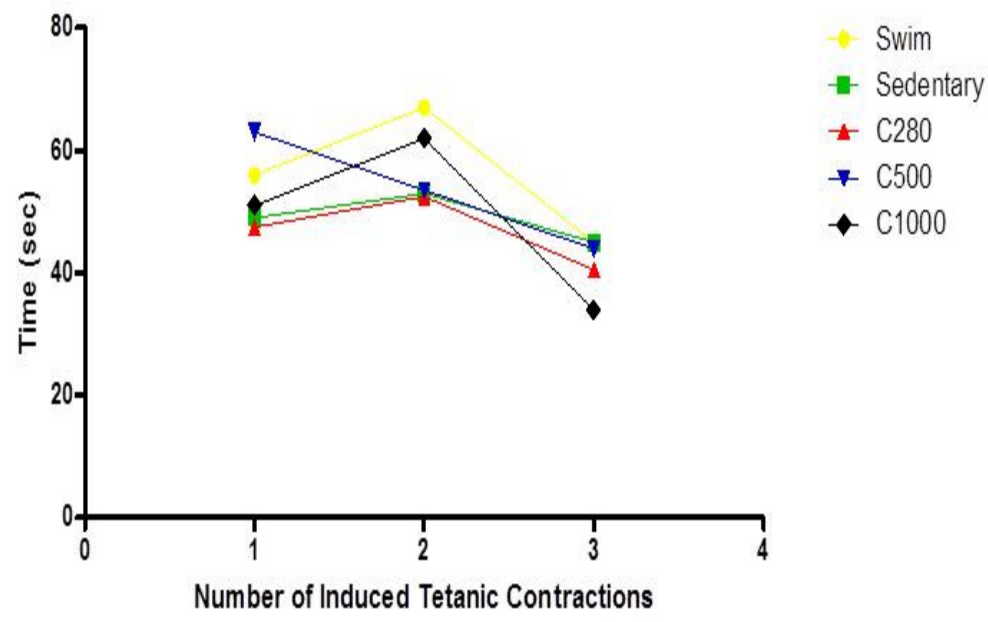

Figure 3. Decay Time of muscle tetanic contraction to $50 \%$ of maximum tension. Values for the contraction decay time in each group, at the three different moments ( $n=6 /$ group).

Decay Time of muscle tetanic contraction

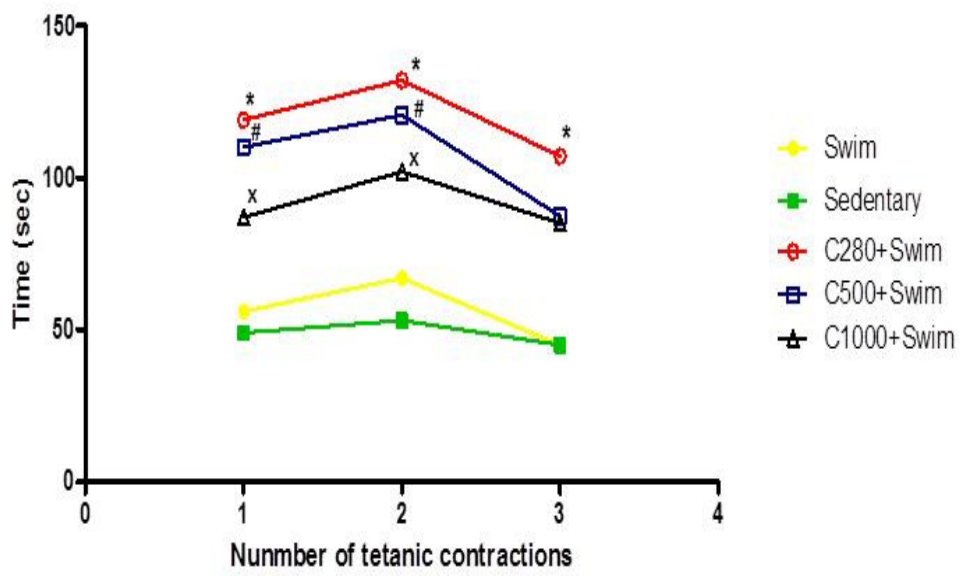

Figure 4. Decay Time of muscle tetanic contraction to $50 \%$ of maximum tension. Values for the contraction decay time in each group, at the three different moments ( $n=6 /$ group. ${ }^{*} \mathrm{p}<0.05$ vs all sedentary/supplemented groups; ${ }^{\#} \mathrm{p}<0.05$ vs all sedentary/supplemented groups, ${ }^{\mathrm{x}} \mathrm{p}<0.05$ vs all sedentary/supplemented groups).

Figures 5 and 6 show the effect of $\mathrm{Crm}$ supplementation over the area under the curve (AUC) of the time necessary for the contraction intensity to decline to $50 \%$ of the maximum contraction. It is possible to consider the area as the musculature capacity to endure fatigue in high contractile tension circumstances. Figure 6 shows that at T2 and T3 there was a significant increase in the $\mathrm{C} 280+$ swim group $(2.76 \pm 0.25$ and $2.65 \pm 0.54$ respectively), when compared to the other groups. 


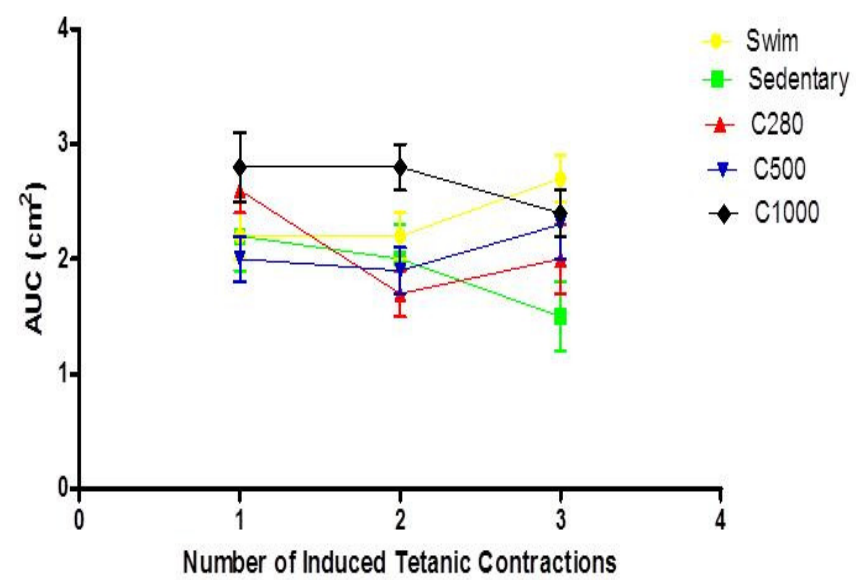

Figure 5. Area under the curve for the intensity $x$ time ratio. The data report area under the curve for each group at the three distinct moments of the electrostimulation muscle contraction protocol ( $\mathrm{n}=6 /$ group).

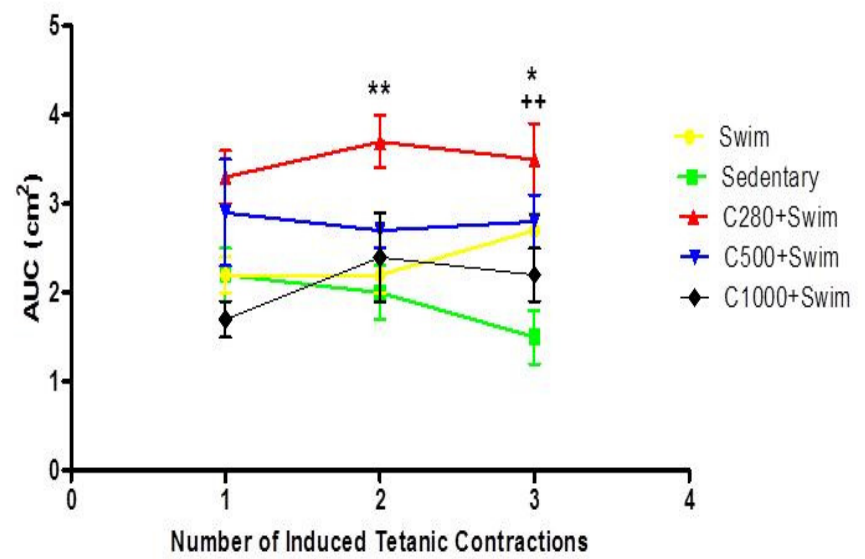

Figure 6. Area under the curve for the intensity $x$ time ratio. The data report area under the curve for each group at the three distinct moments of the electrostimulation muscle contraction protocol $(\mathrm{n}=6 /$ group; $* * \mathrm{p}<0.01$ C280+swim vs other groups and $++\mathrm{p}<0.01 \mathrm{C} 280+$ swim vs C500+swim).

The AST plasmatic analysis (Figure 7) 280+swim group presented statistical significance when demonstrated high values for the $\mathrm{C} 280$ group that were compared to: sedentary, swim, and C1000+swim significantly superior to the values of the sedentary, groups.

swim, C500, C1000, and C1000+swim groups. The

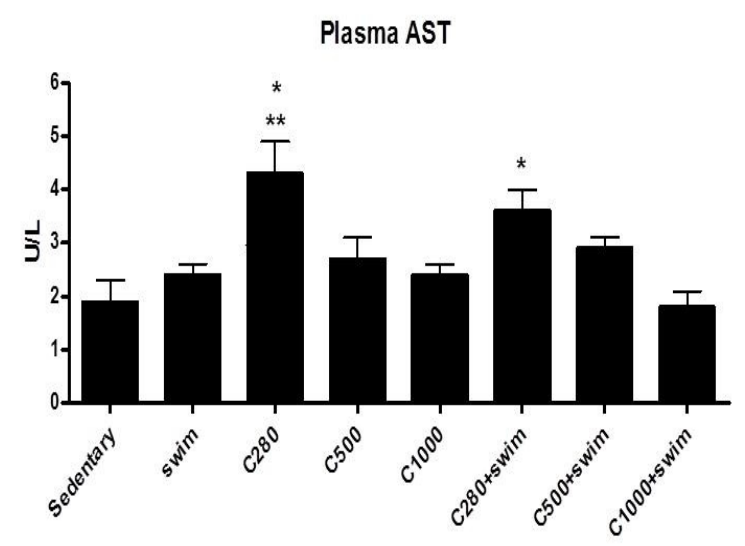

Figure 7. Basal concentration of plasma AST in the control group and AST concentration in the other groups after treatment and the application of indirect electrical stimulation $(n=6 ; * p<0.05$ C280 vs C500+swim; $*_{*}^{*} \mathrm{p}<0.01 \mathrm{C} 280$ vs sedentary, swim, C500, C1000 and C1000+swim; ${ }^{\mathrm{p}}<0.05 \mathrm{C} 280+$ swim vs sedentary, swim, C500, C1000, C500+swim and C1000+swim). 
The values of plasmatic LDH (Figure 8) show significantly higher levels in all groups when compared to $\mathrm{C} 280+$ swim group and swim group.

Plasma LDH

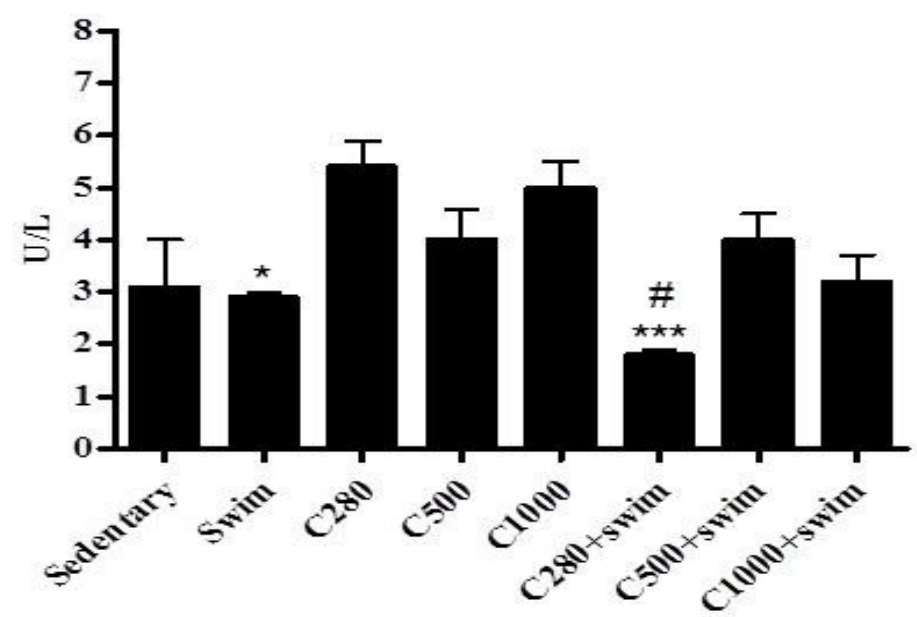

Figure 8. Basal concentration of plasma LDH in the control group and LDH concentration in the other groups after treatment and the application of indirect electrical stimulation $(\mathrm{n}=6 ; * * * \mathrm{p}<0.001 \mathrm{C} 280+\mathrm{swim}$ vs sedentary,C280, C500, C1000, C500+swim and C1000+swim; " $\mathrm{p}, 0.05$ C280+swim vs Swim; *p $<0.05$ Swim vs C280, C500, C1000, C500+swim and C1000+swim).

The urea concentration values (Figure 9) statistical analysis considering that all the groups presented a very small variation, which was verified by presented samples with no significant differences.

\section{Plasma urea}

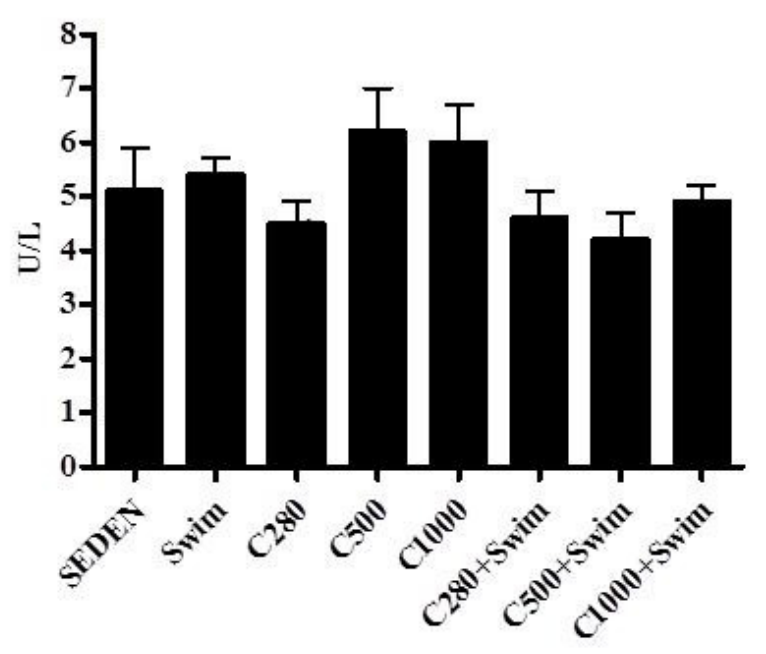

Figure 9. Basal concentration of plasma urea in the control group and urea concentration in the other groups after treatment and the application of indirect electrical stimulation $(n=6)$.

\section{DISCUSSION}

Cr supplementation, which aims to increase PCr stocks, leads to higher ATP resynthesis capacity (GREENHAFF, 1997; TERJUNG et al., 2000; RICO-SANZ, 2000).

Regarding this affirmation, the present study did not observe correlations between this resynthesis and the maximum contraction intensity. It must be taken into account that the induction of maximum contraction by electrostimulation induces a very brief intensity "peak", with the recruitment of all motor units, in which the duration is maintained for less than 1 second, and that during this interval there is no occurrence of an intense ATP depletion capable of harming the maintenance of the maximum initial tension level (intensity). Thus, $\mathrm{Cr}$ supplementation, which aims to increase $\mathrm{PCr}$ stocks and concomitantly ATP resynthesis, does not seem to cause any effect on the maximum force capacity. 
Besides this, the exercise protocol also demonstrated little or no influence regarding the quality of coordination of intramuscular recruitment of these animals. This fact was expected, since the training did not stimulate the organism to neural adaptation, considering that the activity presents low intensity when compared to the stimulated contraction intensity. The supplementation and type of exercise applied, or both, did not alter this variable.

Swimming exercise can stimulate the oxidative fibers and maintain the intensity of exercise longer; the hypothesis is that swimming training develops an aerobic potential capable of helping in metabolite resynthesis through catchment and use of lactate, in this way extending resistance to fatigue. The values regarding the time of resistance to intense contraction (up to $50 \%$ of the maximum contraction) presented interesting numbers (Figures 3 and 4). In this variable, the groups treated with creatine+exercise, with the best results found in the C280+swim group, demonstrated the highest values in the test. The C280+swim group presented values ranging between 2 and 3 minutes, a length of time that allows an intense break of phosphagens and contribution of energetic glycogenic resources, but not enough time to allow the aerobic system to contribute with predominance in the immediate energy offer (ARMSTRONG; BARKER, 2011). Since the fast-twitch fibers are predominantly required for fatigue induction, its tensional contribution suggests that the whole energy depletion process, metabolite production, alterations in the membrane, and the fatigue process occur in these fibers.

The results of the exercise supplemented groups raised the hypothesis that the insulin potential has influence in this adaptation. It is known that insulin has a potential effect in the absorption of $\mathrm{Cr}$ by the muscle (KIM et al., 2001). This effect can be considered determinant, since the supplemented group that performed the exercise presented greatly superior data results in comparison with the group that was only supplemented; although it is not totally clear, it is known that exercise leads to an increase in insulin potential in the muscle membrane. The increase in the supplement doses did not generate an increase in these gains, although the execution of exercises led to improvements in the creatine+exercise group. On the other hand, the values presented a decrease as the doses increased. A hypothesis for this behavior is the protection regulator effect of the organism in the transport of creatine transporter, which presents an inversely proportional relationship to the $\mathrm{Cr}$ offered in the plasma. (MURPHY et al., 2001)

The capacity to endure a high load for the longest time possible is reported in Figures 5 and 6 in the area under the curve (AUC), highlighting an expressive gain in the creatine+exercise group (C280+exerc) when compared to the others. This information points to the influence of physical activity in the utilization of energetic substrates and their routes for degradation, differently from what is demonstrated in the isolated supplementation that increases the performance of high intensity activities. $\mathrm{Cr}$ supplemented volunteers did not present effects when they did not practice exercises, in the maximum potency peak or in resistance to fatigue in 5 sessions of 10 seconds of intermittent maximum exercise on a stationary bicycle (McKENNA et al., 1999). This highlights that exercise acts in ways which are not yet clear, over the improvement of the utilization and resynthesis of energetic substrates in the $\mathrm{Cr}$ supplemented groups. As well as in the case of the resistance time to the decrease of $50 \%$ of maximum contraction, relating to the behavior of the supplemented groups with higher doses, it is possible to suggest the regulator effect in the transport of $\mathrm{Cr}$, depending on the offer of this substrate in the intracellular environment, once again showing that high levels of $\mathrm{Cr}$ can make the organism act in a protective manner in the transportation (MURPHY et al., 2001), presenting a decrease with high doses, corroborating the data presented by the groups that were only supplemented with higher doses of $\mathrm{Cr}$ (C500 and C1000). Such performance was also found in the groups with physical activity, raising questions about the influence of high doses of drugs in this process.

Analysis of the plasmatic metabolites reflects the muscular performance aspects and basic physiological functions in exercise. In this research, the plasmatic level of the AST and LDH enzymes was observed, in addition to the final metabolism substance, the urea, in order to estimate the cause-effect relation in these concentrations. Many studies report that $\mathrm{Cr}$ supplementation does not present effects on hepatic activity or muscle enzyme release and thus, that supplementation does not present alterations in sedentary healthy individuals or physically active ones (ALMADA et al., 1996; ENGELHARDT et al., 1998; MIHIC et al., 1998; RANSOM et al., 1999). Though the preliminary findings suggest that $\mathrm{Cr}$ supplementation does not affect the enzymes flow, additional research should be carried out in relation to the serum enzyme release in trained and untrained populations (KIM et al., 2001).

The aspartate aminotransferase enzyme (AST) is present in deamination reactions; these reactions are 
part of the complex acting in the transformations of various different substrates in glucose. The enzyme action refers specifically to glutamate (main amino acid converged in the organism) plus oxaloacetate transformation, resulting in aspartate and $\alpha$ ketoglutarate, this entering the cycle of Krebs for the aerobic production of ATP. The circulating lactate represents an important metabolite stimulatory of the gluconeogenesis process. Besides this, other factors contribute to activate the gluconeogenesis process, such as muscular concentration of glycogen and blood glucose (KIM et al., 2001). Due to the duration of the protocol application to induce fatigue (3 contractions of about 1 minute distributed over 30 minutes) (Figure 7), we suggest that the expression of values of this enzyme activity (AST) obeyed the necessity to activate the ATP and glucose production mechanism through the amino acids (gluconeogenesis), potentiated by the presence of circulating lactate (as in the C280+exerc and C280 groups).

The lactate dehydrogenase enzyme (LDH) is present in the muscles, liver, kidneys, and myocardium, participating in the reaction of lactate in the pyruvate reaction. Therefore, high levels of lactate in the organism lead to a high expression of this enzyme, a very noxious substance to the organism in high rates (SANTOS, 2016). A well-conditioned musculature is capable of removing and metabolizing this substance faster, by removing it through the bloodstream and/or by $\mathrm{LDH}$ action (KIM et al., 2001). We highlight that well-conditioned muscle presents the capacity to use pyruvate through the aerobic system in slow-twitch fibers, and in fast-twitch fibers with high performance characteristics, great capacity to produce lactate (KIM et al., 2001).

This type of research approaches training with exercises, swimming in this case, which present aerobic characteristics and predominate the slow-twitch fibers. If they work well, these fibers can act in the removal process of this muscle lactic acid produced by fasttwitch fibers through absorption and use of lactate as an energy source. Supplementation with exercise can increase the aerobic capacity of these slow-twitch fibers, (AGUIAR et al., 2010) which suggests a potential influence of this mechanism in the values expressed by the C280+exerc groups (Figure 8). As they are not recruited in maximum efforts (as in tetany), these fibers can maintain their functions without the interference of lesions or alterations in their membrane. This raises the hypothesis that the size of the plasmatic LDH activity is not changed by enzymatic reactions of this same enzyme, which acted in the intracellular ambience of the slow-twitch fibers, adjacent to the fast-twitch ones used in tetany.

Urea represents the principal pathway for excretion of amino groups involved in deamination. Increases in its concentration refer to overcharges in renal function (CORSETTI et al., 2016). The data presented similar behavior, in which the C500 and C1000 groups demonstrated apparently higher values, suggesting a possible function increase. In addition, with the dose increase, we observed in both groups (only supplement and supplement+exercise) an elevation in values, except for the C500+exercise group (Figure 9). Since it is a final metabolism excretion, concern about values should be greater, as people tend to confuse quality with quantity and, in this case, high doses of creatine can increase the workload of the kidneys.

In conclusion, supplementation with Crm demonstrated significant ergogenic effects when accompanied by exercise practice and the recommended dose $(280 \mathrm{mg} / \mathrm{kg})$, and demonstrated worse effects at higher doses. The C280+swim group presented the best results in time of resistance to intense contraction (muscular fatigue) in short times (ranging between 2 and 3 minutes). However, it was not capable of altering the maximum intensity of the musculature tension. However, the supplementation itself does not seem to exert an ergogenic effect on this specific adaptation.

Therefore, the influence of exercise in the energy metabolic capacity seems evident, using supplementation to strengthen these effects.

RESUMO: O objetivo do presente estudo foi investigar os efeitos de diferentes doses de suplementação oral de creatina sobre a resistência e fadiga do músculo tibial em ratos wistar. Os protocolos de tratamento incluíram exercícios de natação, suplementação isolada (doses diferentes) e suplementação (doses diferentes) + exercícios de natação. A análise do efeito da suplementação de creatina na fadiga do músculo esquelético foi realizada utilizando-se a intensidade da contração muscular à uma estimulação elétrica, aferindo a intensidade da contração muscular, tempo de decaimento da contração tetânica do músculo a $50 \%$ da tensão máxima (fadiga) e a área sob a curva para a razão de intensidade x tempo, além de análises plasmática de AST, LDH e ureia. Nossos resultados sugerem que a suplementação de creatina parece ser capaz de produzir efeitos ergogênicos no metabolismo contrátil no grupo tratado, com a dose de $280 \mathrm{mg} / \mathrm{kg}+$ natação. Esta dose de creatina teve um aumento estatisticamente significativo no tempo de decaimento da contracção tetânica muscular

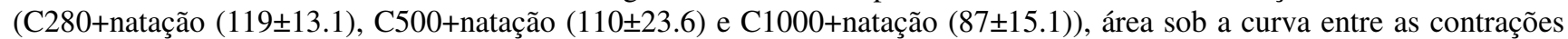
tetânicas e também diminuição da LDH plasmática quando comparada com as outras doses. Estes dados demonstraram claramente que doses elevadas não conduzem a qualquer aumento adicional de efeitos ergogênicos. Concluimos que a 
dose de $280 \mathrm{mg} / \mathrm{kg}$ + exercício de natação obteve os melhores efeitos ergogênicos sobre a resistência e fadiga do músculo tibial em ratos wistar.

PALAVRAS-CHAVE: Creatina. Exercício. Fadiga. Contração tetânica. Suplemento dietético.

\section{REFERENCES}

AGUIAR, A. F. et al. Effects of creatine supplementation during resistance training on myosin heavy chain (MHC) expression in rat skeletal muscle fibers. J. Strength Cond. Res. v. 24, p. 88-96, 2010. https://doi.org/10.1519/JSC.0b013e3181aeb103

ALMADA, A.; MITCHELL, T.; EARNEST, C. Impact of chronic creatine supplementation on serum enzime concentration. FASEB J., v. 10, 1996.

AOKI, M. S.; Suplementação de creatina e treinamento de força: Efeito do tempo de recuperação entre as séries. Rev. Bras. Ci e Mov, Brasília, v. 12, n. 4, Dez. 2004.

ARAUJO, M. B.; MOURA, L. P.; JUNIOR, R. C. Creatine supplementation and oxidative stress in rat liver. J. Int. Soc. Sports Nutr. v. 10, p. 54, 2013. https://doi.org/10.1186/1550-2783-10-54.

ARMSTRONG, N.; BARKER, A.R. Endurance training and elite young athletes. Med. Sport. Sci. v. 56, p. 5983, 2011. https://doi10.1159/000320633

BRANCH, J. D. Effect of creatine supplementation on body composition and performance: a meta-analysis. Int. J. Sport. Nutr. Exerc. Metab. v. 13, p. 198-226, 2003.

CORSETTI, R. et al. Changes in urinary amino acids excretion in relationship with muscle activity markers over a professional cycling stage race: in search of fatigue markers. Amino Acids. V. 48, p. 183-192, 2016. https://doi10.1007/s00726-015-2077-z

DE ARAUJO, G. G.; PAPOTI, M.; MANCHADO, F. B.; MELLO, M. A.; GOBATTO, C. A. Protocols for hyperlactatemia induction in the lactate minimum test adapted to swimming rats. Comp Biochem Physiol A, Mol Integr Physiol n. 148, v. 4, p. 888-892, 2007. https://doi10.1016/j.cbpa.2007.09.002

DEMINICE, R.; JORDAO, A. A. Creatine supplementation reduces oxidative stress biomarkers after acute exercise in rats. Amino Acids, n. 43, p. 709-715, 2012. https://doi10.1007/s00726-011-1121-x.

ENGELHARDT, M. NEUMANN, G.; BERBALK, A.; REUTER, I. Creatine supplementation in endurance sports. Med. Sci. Sports Exerc. V. 30, p. 1123-1129, 1998. https://doi10.1097/00005768-199807000-00016

GREENHAFF, P. L. The nutritional biochemistry of creatine. Nutr. Biochem. 1997.

https://doi.org/10.1016/S0955-2863(97)00116-2

LOPES-MARTINS, R. A. B. et al. Effect of low-level laser (Ga-Al-As $655 \mathrm{~nm}$ ) on skeletal muscle fatigue induced by electrical stimulation in rats. J Appl Physiol, n. 101, v. 1, p. 283-8, 2006.

KIM, H. J.; KIM, C. K.; CARPENTIER, A.; POORTMANS, J. R.; Studies on the safety of creatine supplementation. Amino Acids, n. 40, n. 5, p. 1409-18, 2001. http://doi10.1007/s00726-011-0878-2

KIM, J.; LEE. J.; KIM, S.; YOON, D.; KIM, J.; SUNG, D. J. Role of creatine supplementation in exerciseinduced muscle damage: A mini review. J Exerc Rehabil. v. 11, n. 5, p. 244-250, 2015.

http://doi10.12965/jer.150237. 
McKENNA, M. J.; MORTON, J.; SELIG, S. E.; SNOW, R. J. Creatine supplementation increases muscle total creatine but not maximal intermittent exercise performance. J Appl Physiol. v. 87, n. 6, p. 2244-2252, 1999.

MIHIC, S. et al. The effect of creatine supplementation on blood presure, plasma creatine kinase, and body composition. FASEB J. v. 12, 1998.

MURPHY, R. et al. Creatine transporter protein content, localization, and gene expression in rat skeletal muscle. Am. J. Physiol. Cell. Physiol., 2001.

PERSKY, A. M.; BRAZEAU, G. A. Clinical Pharmacology of the Dietary Supplemet Creatine Monohydrate. Pharmacol Rev, v. 53, n. 2, p. 161-176, 2001.

RAMOS, L. et al. Infrared (810 nm) Low-Level Laser Therapy in Experimental Model of Strain-Induced Skeletal Muscle Injury in Rats: Effects on Functional Outcomes. Photochem Photobio, v. 88, p. 154-160, 2012. http://doi10.1111/j.1751-1097.2011.01030.x.

RANSOM, J. et al. Effects of creatine supplementation during training on markers of catabolism and muscle and liver enzymes. Med. Sci. Sports Exerc. v. 31, s. 265, 1999.

RICO-SANZ, J. Creatine reduces human $\mathrm{PCr}$ and $\mathrm{pH}$ decrements and $\mathrm{Pi}$ accumulation during low-intensity exercise. J. Appl. Physiol. v. 88, n. 4, p. 1181-91, 2000.

SANTOS, V. C. et al. Marathon Race Affects Neutrophil Surface Molecules: Role of Inflammatory Mediators. Plos One. v. 11, n. 12, 2016. http://doi10.1371/journal.pone.0166687. eCollection 2016.

TERJUNG, R.L.; et al. AMERICAN COLEGE OF SPORTS MEDICINE ROUNDTABLE. The physiological and health effects of oral creatine supplementation. Med. Sci. Sports Exerc. v. 32, n. 3, p. 706-17, 2000.

VAN LOON, L. J.; OOSTERLAAR, A. M.; HARTGENS, F.; HESSELINK, M. K.; SNOW, R. J.; WAGENMAKERS, A. J. Effects of creatine loading and prolonged creatine supplementation on body composition, fuel selection, sprint and endurance performance in humans. Clin Sci (London), v. 104, n. 2, p. 153-162, 2003. http://dx.doi.org10.1042/CS20020159

ZANELLI, J. C. S.; CORDEIRO, B. A.; BESERRA, B. T. S.; TRINDADE, E. B. S. M. Creatine and resistance training: effect on hydration and lean body mass. Rev. Bras. Med. Esporte. v. 21, n. 1, p. 27-31, 2015. http://dx.doi.org/10.1590/1517-86922015210101932. 